\title{
Brocades of the Southern Cities: Development of Woven Fabric Products in Order to Add Value to Community Economy
}

\author{
Kunthida Nakhasathien ${ }^{1}$, Kla Somtrakool $^{1} \&$ Wisanee Siltrakul $^{1}$ \\ ${ }^{1}$ The Faculty of Cultural Science, Mahasarakham University, Khamriang Sub-District, Kantarawichai District, \\ Maha Sarakham Province, Thailand \\ Correspondence: Kunthida Nakhasathien, Siam Technological College (SiamTech), 46/9 Charansanitwong Rd, \\ Tha Phra District, Bangkokyai, Bangkok 10600, Thailand. E-mail: tantop50@hotmail.com
}

Received: July 11, 2013 Accepted: September 7, 2013 Online Published: November 29, 2013

doi:10.5539/ass.v9n17p128 URL: http://dx.doi.org/10.5539/ass.v9n17p128

\begin{abstract}
This qualitative research examines three weaving groups in the South of Thailand. The study analyzes the local wisdom used in the production of brocades in the Southern cities and the problems and methods of market management for brocades of the Southern cities in order to develop products and add value to the community economy. The results identified a number of problems regarding the limited design experience and abilities of weaving group members, the lack of consumer surveys and high production costs for little financial reward. The article highlights various ways in which these problems can be addressed, including focus on quality production of goods specifically selected by the consumer, reduction of manufacturing costs and creation of group logos and branding. By implementing these suggested developments, the weaving groups will add value to their local community economies and protect their handicraft against the challenges of the global economy.
\end{abstract}

Keywords: brocades, southern cities, development, products, added-value, community economy

\section{Introduction}

Clothing and apparel are one of the four necessities of human life, alongside food, residence and medicine. They help to conceal or cover up, provide warmth and protect from various animal dangers that affect the body. Therefore, clothing and apparel have been important to humans throughout history and humans have always sought for high quality clothing and apparel made from good materials that are colorful, beautiful, rare and with patterns that reveal the local identity. These characteristics come from the building and maturity of steps and methods of natural fabric cultivation for use in the complex and delicate skill of weaving. This handicraft highlights the continued importance and relationship of clothing and apparel to humanity from the ancient world until the present day.

The culture of local cloth creation counts as an artistic handicraft whose identity directly derives from local folk wisdom and reveals the goodness and beauty that has been accumulated and inherited in each area from generation to generation. For Thailand, the lifestyle of past society evolved from the different foundations of race, religion, society, geography, culture and surrounding environment. In each place, there were also customs, traditions and culture that were the specific identities of different groups in each region and enabled them to live happily together in the same society. This was achieved through the sincere acceptance of cultural history, traditions and mutual respect of humanity. However, after World War Two, currents of foreign civilizations rapidly entered Thailand, causing changes to the existing lifestyle, attitudes and values. The effects came from all evolved societies in the world and included advancements in technology. This caused the lifestyle in all corners of the world, including Thai society, to change accordingly. These changes also affected the culture of Thai cloth weaving. In the past, Thai females would weave clothing for self-use within the family or for making merit. Nowadays, there has been an increase in weaving groups for business purposes, which can be seen in analysis of woven goods export figures for three years. In 2004, Thailand exported woven goods to the value of two-thousand one-hundred and sixty-one million dollars. In 2005, Thailand exported woven goods to the value of two-thousand five-hundred and sixty-three million dollars. In 2006, Thailand exported woven goods to the value of two-thousand seven-hundred and sixty-four million dollars (Thailand Textile Institute, 2006, p. 82).

From these export statistics, it can be seen that woven products continually increase in value, which indicates the quality of the product and demand. This may also show that Thai cloth is currently very popular among foreign 
communities. Therefore, foreigners trust the quality of the handicraft and the delicacy of Thai cloth products. In another respect, some areas of society are extremely disappointing, as Thai people overlook the weaving culture and the creativity and processes that have been accumulated, inherited and developed in each era. This means that in the production of just one ream of fabric, the weavers must really try and concentrate to be industrious and delicate and include the local folk wisdom that has been inherited over time. Thai indigenous fabric is considered worthless, out-dated and outmoded by Thai society. By contrast, Thai people appreciate famous and expensive products from abroad. This is shameful and causes a lack of Thai consciousness.

For this reason, Queen Sirikit made a royal initiative about the conservation of indigenous Thai cloth so that it may continue to exist. The initiative involved the creation and establishment of professional artistic centers to conserve the local artistic handicraft that derives from Thai folk wisdom. This also included the support and enhancement of indigenous weaving, so that it became an important cultural identity for Thailand. If this initiative is implemented to be inclusive and more efficient, the related personnel in all areas should look at the prominent characteristics in order to enhance and find weaknesses for the development of Thai fabric product types so that they meet needs and are able to compete with fashion currents and product uses in global society.

Thailand has important fabric in many places, especially the Northern and Northeastern regions. However few people realize that the Southern region has fabric of a similar importance, such as brocades. The brocades in the Southern region consist of patterns on fabric, which are raised differently depending on the pattern. The design will use the same colored cotton or silk throughout. The styles are an original identity, such as Garuda patterns, letter patterns, bird of paradise patterns and fishing hook patterns, which are difficult to find nowadays as there are few elders who are able to weave. For the most part, these elderly weavers have given up the practice. However, the most prominent feature of the past was silver or golden thread, which was previously only used by royalty and noblemen. However, nowadays there is no-one able to weave using these threads because in each location it is common to use contemporary methods, which means the development of ready-made clothing and apparel in response to modern lifestyle.

Nowadays, quotas of indigenous woven fabric cannot be sold and there are big differences between the production and sale totals. This causes financial problems. Therefore, as indigenous woven fabric products are derived from the creativity of local groups in the area, most people use the original methods and production processes, causing a lack of development. Aside from this, there are also problems with the use of bright product colors that stem from a lack of knowledge regarding use of colors with the material. There is also a lack of variety in product designs, which do not meet the needs of the market and consumers because there is no survey of the customer needs before production. One further problem is design imitation and copying, which causes a surplus of products and decrease of product value and has a further effect on financial conditions. The community weaving groups in Southern Thailand that are experiencing the severest problems are Ban Neun Muang Weaving Group, Nakhon Si Thammarat Province, Na Muean Sri Weaving Community, Trang Province and Ban Ta Grajai Weaving Community, Surat Thani Province.

It can be concluded that the financial problems of most weaving businessmen come from a lack of knowledge and understanding among weavers regarding product designs that meet consumer needs, the decreasing value of the products and, importantly, the lack of market survey before production. This causes the businessmen to be unable to compete and sell woven products to their full potential. Therefore, the research team considered helping by creating understanding and providing knowledge about product designs that are different from the originals in order to solve the problems and enhance the handicraft so that people in the community have a lasting occupation and are able to help and depend on themselves, as well as adapting perspectives regarding consumers so that they are confident in the product forms. This would involve creation of products that rely on social needs but remain true to the local identity of the area in order to create product variety as a selling point and create prominent features for brocades that are accepted by and meet the needs of the market. In this way, the research is a way to promote and conserve Thai brocades so that they continue to exist in the future.

\section{Research Aims}

This research has three main research aims: a) to study local wisdom used in the production of brocades in the Southern cities; b) to study the problems and methods of market management for brocades of the Southern cities in order to add value to the community economy; c) to develop products from brocades of the Southern cities in order to add value to the community economy. 


\section{Research Methodology}

\subsection{Research Area}

This qualitative research collected data from documentary study and field research. The contents of this research were the local wisdom used in the production of brocades in the Southern cities, the problems and methods of market management for brocades of the Southern cities in order to add value to the community economy and development of products from brocades of the Southern cities in order to add value to the community economy. This research was conducted over fourteen months, beginning in October 2010 and ending in December 2012. The research area consisted of Ban Neun Muang Weaving Group, Nakhon Si Thammarat Province, Na Muean Sri Weaving Community, Trang Province and Ban Ta Grajai Weaving Community, Surat Thani Province. The sample population included community representatives, weavers, government representatives, design experts, general people and people who purchased brocade products. The population totaled thirty-eight people.

\subsection{Research Tools and Methodology}

Data for this study was collected by document study and field research. The tools used in field data collection included observation, interview, focus group discussion and workshop. These research tools were used with the research population, broken down into three groups: eight key informants, fifteen casual informants and fifteen general informants. The data was validated using a triangulation technique and analyzed according to the three research aims. The results are here presented as a descriptive analysis.

\section{Research Results}

\subsection{Local Wisdom Used in the Production of Brocades in the Southern Cities}

In the past, Ban Neun Muang, Nakhon Si Thammarat Province and Ban Na Muean Sri, Trang Province used natural cotton fibers and dyes. Ban Ta Grajai in Surat Thani Province was the only place that used manufactured silk and cotton fibers and chemical dyes. The people began to create woven brocades as a development from loincloths, sarongs, pa nung and cloth used in ceremonies. The design method used calculation and imagination to create new patterns from the original styles or adopted methods of trial and error. The ancient designs were also all inherited. There was no product design because the products were created for use in the home.

Nowadays, the materials include all types of cotton and chemical dyes. However, Ban Ta Grajai Weaving Community use genuine silk and both chemical and natural dyes. The patterns of all weaving groups are designed using a method of putting patterns on a graph, except the Ban Ta Grajai Weaving Community, who inherit the patterns from ancestors. The popular patterns of Ban Neun Muang Weaving Group differ each year because every member of the group presents about four patterns per year and these patterns are changed for the following year. In Na Muean Sri Weaving Community there is a variety of popular patterns. For Ban Ta Grajai Weaving Community, the popular pattern is the Rachawat pattern. Teachers from the Ministry of Industry come to help with product design in all groups and each group uses its experience in design. However, for the most part, the groups are unable to create their own designs. General products in each group include shirts, bags, neckties, cloth bags, scarves and flannels.

\subsection{The Problems and Methods of Market Management for Brocades of the Southern Cities in Order to Add Value to the Community Economy}

\subsubsection{Problems}

This research identified a number of key problems. Fibers are expensive and the fiber colors are not consistent. Groups use colors that are too bright, which causes difficulty in selling the cloth. The three groups are unable to design products themselves and the products do not meet the needs of the customers. No group has members able to design products. The consumers want the products to be more up-to-date and adapted in a variety of different ways. The income from production and sale is small because the employment costs of the South are high and the members are required to reduce the sale price of goods in order to compete when selling outside of the community area. This means that when customers come to buy within the community, prices must be adjusted to match those seen in the external markets. The weaving groups rarely sell their products outside of the area because there are high associated transport and employment costs.

\subsubsection{Methods of Market Management}

From the problems discussed, a number of solutions are possible. A large quantity of materials must be ordered to reduce the material and transportation price. There must be study and survey of the market regarding the direction of color trends for adaptation and use with materials. There must be survey of the customer trends to discover what products are in demand and design of the products so that they are up-to-date and consistent with 
customer needs. Methods must include work study and participation in development seminars in different places. There must be market survey in order to know the consumer needs. The management method must start from the selection of raw materials, fibers, colors and product design so that products are up-to-date and of high quality, which will enable the income to increase. Aside from this, sale of products in shops outside the community weaving centers has an effect on sale within. Regarding the price discounts, the entire group must agree on prices so that there is certainty over the amount that prices may be reduced. The groups must wait for various institutions to help in finding locations of sale and covering the additional costs. There must be market planning and understanding between members of the group regarding the areas that require adaptation. New ways must be found to sell products by selling outside the area, so as to find new customers.

\subsection{Development of Products from Brocades of the Southern Cities in Order to Add Value to the Community Economy}

From consumer and producer surveys, it was discovered that there is consumer demand for clothing and bags. There are some differences in producer demands. Ban Neun Muang Weaving Group wish to produce bags, shoes and notebook cases. The Na Muean Sri Weaving Community require home decorations and male and female clothing. The Ban Ta Grajai Weaving Community want clothing, bags and bath robes.

Product design must respond to the consumer and producer needs. The researchers created five designs for each product form, which was reduced to a final design by the consumers. Finalized products for Ban Neun Muang Weaving Group were travel bags, sandals and notebook cases. Finalized products for the Na Muean Sri Weaving Community were pillow-cases, table-cloths, male suits, informal clothes, work clothes and gowns. Finalized products for Ban Ta Grajai Weaving Community were work clothes, gowns, bath robes and bags.

Products should be developed to include the local identity. The researchers produced goods and made a brand logo for each group in order to reveal the local identity. The identity of the Ban Neun Muang Weaving Group is their sole use of cotton and floral patterns. The group finalized bag prices at 500 baht, from a production cost of 400 baht. Sandals were sold for 199 baht, from a production cost of 134 baht. Notebook cases were sold at 950 baht, from a production cost of 250 baht. The group logo was a Phra That Chedi. The identity of Na Muean Sri Weaving Community was the use of waxed cotton in the weaving process and original, ancient patterns. The group selected the pillow case price from 3000 to 3500 baht from a production cost of 1400 baht. The table cloth price was set at 3500 from a production cost of 1828 baht. Male suits were sold from 2500 to 3000 baht, from a production cost of 1800 baht. Informal clothes were sold at 2000 baht, from a production cost of 1280 baht. Work clothes were sold for 3000 baht, from a production cost of 1600 baht. Gowns were sold from 5000 to 8000 baht, from a production cost of 3000 baht. The group logo was the cloth used by the group to compete for the outstanding Indigenous Cloth in the Southern Region. This cloth used flowers from the Jacaranda Tree and the poem of the Na Muean Sri Weaving Community. The identity of the Ban Ta Grajai Weaving Community is in its use of genuine silk, which is used to create floral brocades and contains silver and gold thread. The price of work clothes was set from 1500 to 1800 baht, form a production cost of 820 baht. Gowns were set at 8000 baht, from a production cost of 3800 . Bath robe prices were set at 1000 baht from a production cost of 500 baht. Bags were sold for 2800 baht, from a production cost of 1200 baht. The group logo was the Grajai flower and letters used as pillars of the logo.

\section{Discussion}

\subsection{Local Wisdom Used in the Production of Brocades in the Southern Cities}

The local wisdom in each of the three groups uses manufactured cotton and genuine silk, chemical and natural dyes, various patterns that have been inherited from the past and new patterns that have been adapted from original styles or created through trial and error. Most patterns will take the names of flowers, which agrees with the research of Kanitta Tantipimon and Suwimon Sagunded (1993, p. 1). Their research concerned cloth patterns, their meanings and the folk wisdom revealed in Thai fabric in three Southern provinces. The findings were that there are six types of fabric patterns in the South, which are: a) original patterns from the past; b) adaptations of original patterns; c) imitations of domestic patterns from elsewhere; d) imitations of foreign patterns; e) mixtures of original patterns and patterns from elsewhere; f) newly invented patterns. It can be concluded that it is popular for most weaving groups in the South to use patterns from their ancestors. Sometimes, there may be new patterns that are mixtures of the old and new patterns, which show that the weaving groups maintain the wisdom of the past. 


\subsection{The Problems and Methods of Market Management for Brocades of the Southern Cities in Order to Add Value to the Community Economy}

This research found that each of the three groups uses manufactured cotton and genuine silk. Fibers are ordered from Bangkok but are expensive. This corresponds with the research of Pattamawadee Chansuwan (2009, p. 241-246), which found that producers of accessories in Isan encounter problems with raw materials ordered from Bangkok. This increases transportation costs. Aside from this, there is not enough sponsorship funding. For this reason, the solution is to order a large quantity of materials to reduce the material and transportation price or find materials in the surrounding area.

Results regarding product design from this research found that the groups were unable to create their own designs, causing the designs in each group to be similar and fail to meet the needs of the market, which corresponds to the results of Adisorn Srichat (2007, pp. 226-229). Srichat studied the transformation of pa prae wa product forms and found three transformations: a) clothing; b) accessories; c) appliances and utensils. The research results also correspond to those of Silpakorn University (2000, p. 198), who studied indigenous woven cloth and a survey of producers nationwide. The problems and obstacles to production and sale in Ban Mamuang Blay Kaen, Ban Mamuang Kao and Ban Mamuang Dalod in Nakhon Si Thammarat were with seminars or inheritance of the art of weaving and the transformation of products that correspond to the identity and market demand. Therefore there should be a survey to find the up-to-date demands of the customers and production of new products that are modern, various and meet consumer needs. Alternatively, there should be development of existing products so that they are of a higher quality and creation of a model for increasing product value.

The results of this research found that the members of the weaving groups did not have the required knowledge of product design, which corresponds to the theory of self-dependent development of rural communities in the research of Sanya Sanyawiwat (2007, pp. 103-106). This theory stated that for rural communities to depend on themselves and be able to develop there must be a balance between technology, economy, resources, mentality and society (and culture). These are referred to by the acronym TERMS. The findings of this study also agree with the self-development strategy and rural development strategy of Korean academic Park (1998, p. 4370-A). There were three types of strategy according to Park. Firstly there must be a balance between heavy industry, light industry and agriculture. Secondly, industry must be carried out using domestic resources and domestic capital. Thirdly, technology must be developed and production increased by focusing on the management of human resources and the results of the work. From this theory, it can be concluded that people should be supported as much as possible by data, news and technology, whether it is the Internet, magazines or by participation in external seminars. This will strengthen the group thinking and make the whole group cooperate and think creatively together as the level of the workers will be equal. There will be no reliance upon single individuals. If this is possible, the methods and products that are produced will be more varied and interesting.

Regarding the markets, the Southern brocades are more expensive than in other areas because the employment costs are higher. The product process will only cover the material and employment costs, with minimal profit. This causes the income to be less that it should and corresponds to the research of Tasanawalai Promsaen (2004, pp. 131-135). Promsaen studied the method of developing market strategies of OTOP among production groups of silk prae-wa fabric in Kalasin Province and found that the producers did not make a clear production plan. The production depended on the needs of the customers and investment capital. The product price depended on the production cost and the sale of products generated low prices. Therefore, the management method must begin with the fabric selection, colors and product design so that they are up-to-date, of a high quality and sale must take place outside of the production area. These things will all enable value creation for the products and the community economy.

Another factor is that no group focuses on taking the product to present to the customer because there are additional transportation costs that cause them to wait for assistance from government institutions. This corresponds to the research of Schonwald (2000, p. 46), which concerned marketing strategies. Regarding the perspectives of sale and marketing, the research found that community banks in America instructed marketing officers with sales experience from sales business to cover the sales culture, define the market environment, the creation of brands and logos and the establishment of objectives. This study also corresponds to the findings of Collins-Dodd and Louviere (1999, pp. 1-13) regarding methods of market movement of brand products so that they are accepted. Their research into brand equity and retailer acceptance of brand extension found that with different brands there are two methods of market movement so that the products are accepted, which are the decrease of investment capital and the increase of market opportunities. For other techniques, such as advertisement, bulk sale or quality comparisons with competing retailers, the methods will not be the same. From these conclusions, the research team can conclude that good sales techniques must include three 
components, which are: a) the three groups must go to the customer, so as to know the consumer needs in each product; b) the groups must go to the market, so as to know the sale location and the clear needs of the target group; c) the groups must go to the sponsors in order to be familiar with financial conditions in purchase and sale. These three components are very important for the development of community products because community products have more limitations and differences that other products. Therefore if the weaving groups are able to use the concepts in this research as methods of market management, it will help the community products to be stronger and more lasting.

\subsection{Development of Products from Brocades of the Southern Cities in Order to Add Value to the Community Economy}

Regarding the development of products from Southern brocades in order to add value to the community economy, it was found that products include bags, sandals, notebook cases, pillowcases, tablecloths, informal clothes, gowns, work clothes, male suits and bath robes. Prior to the design stage there must be surveys to assess consumer and producer requirements, design principles must be used and there must be consideration of the realistic use of the finished products, the beauty of the products and whether the products are up to date by consulting product and clothing design experts. The reasons for selection of products in the three Provinces were based on the quantity of brocades required to create the product, the beauty of the product form and its real usage. These things correspond to the aesthetic theory of Wanida Kamkiaw (n. d.). Kamkiaw concluded that the artistic views of each person are varied and depend on the selective principles of each person. For most people, the decisions will be made individually and for this reason, the founding and most important principle of good products, discounting those products with a large variety, must be beauty according to consumer tastes. These findings also agree with the research of Pang-Lo Liu, Wen Chin Chen and Chih Hung Tsau (2005, p. 637-644), which studied the correlation between the knowledge management method and new product development strategy on product performance in Taiwan's industries. The results found that scientific and technological progress and other changes occur rapidly in the sales market. The product life-cycle is decreased from before and the companies must adapt and change quickly and research new products by choosing products that are suitable for new technologies and knowing the customer needs and the competition. Development strategies for new products are important and will help the company continue to exist and should be adapted and changed continuously. Therefore, one way to make the producers understand the needs is study of knowledge related to modern trends or fashion progress in order to take these concepts and develop them and create new products that correspond to the needs, likes and tastes of the consumer as much as possible. Aside from this, hanging logo designs are one way to show the local identity, which the researchers studied using information in books and from speaking to locals. This corresponds to the Symbolic Interactionism Theory, which states that social interaction between different groups derives from the effect of translating or understanding meanings of actions. Interaction is not direct from the actions of people but derives from the meanings of these actions. Consequently, interaction is the use of symbols, interpretation and assignment of the true meaning of different actions. Expression in the characteristics of different actions and reactions must be in the form of processes that people understand, are able to evaluate, assign a meaning to and decide upon a response (Srisantisuk, 2001, p. 139). From this theory, it can be concluded that the design of hanging signs creates symbols between consumers and products in order to enable the consumers to know the background of the products. Additionally, they are a way to create an identity for the product that makes the consumer accept the product and also adds value to that product.

In conclusion, the members of each weaving group must participate in thinking, production and development. The members must decide for themselves which products to produce by taking existing fabrics and brocades and transforming them into different products by incorporating other materials that can be found in the community or market area and can be used for the current generation. This will add value to the fabric and assist its sale locally, domestically and internationally. Moreover, the creation of logos for each group and their continued use will also add-value to the community economy.

\section{References}

Chansuwan, P. (2009). The development of accessory inventions in acting in order to add value to the Isan community. Maha Sarakham: Mahasarakham University.

Collins-Dodd, C., \& Louviere, J. (1999). Brand equity and retailer acceptance of brand extension. Journal of Retailing and Consumer Services, 6(1). http://dx.doi.org/10.1016/S0969-6989(97)00039-8

Kamkiaw, W. (n. d.). Aesthetics. Nontaburi: P.S. Print. 
Pang-Lo, L., Wen, C. C., \& Tsau, C. H. (2005). An empirical study on the correlation between the knowledge management method and new product development strategy on product performance in Taiwan's industries. Technovation, 24(12).

Park, P. H. (1998). The Development Strategy of Self-Reliance (JUCHE) and Rural Development in the Democratic People's Republic of Korea. University of California: Riverside.

Promsaen, T. (2004). Methods of Market Strategy Development. Maha Sarakham: Mahasarakham University.

Sanyawiwat, S. (2007). Development Theories and Strategies for Society. Bangkok: Chulalongkorn University.

Schonwald, J. (2000). Core Marketing strategies. Community Banker, 9.

Silpakorn University. (2000). Indigenous Woven Fabrics in the South. Bangkok: Ammarin Printing and Publishing.

Srichat, A. (2007). Local wisdom in production, product transformation and product management of pa prae wa, Kalasin Province. Maha Sarakham: Mahasarakham University.

Srisantisuk, S. (2001). Study of Society and Culture: Concepts, Methodology and Theory. Khon Kaen: Khon Kaen University.

Tantipimon, K., \& Sagunded, S. (1993). Study of Thai Fabric Patterns in the Southern Region. Bangkok: Department of Cultural Promotion.

Thailand Textile Institute. (2006). Statistics of Woven Thai Products. Bangkok: Perfect Plus Design and Print.

\section{Copyrights}

Copyright for this article is retained by the author(s), with first publication rights granted to the journal.

This is an open-access article distributed under the terms and conditions of the Creative Commons Attribution license (http://creativecommons.org/licenses/by/3.0/). 